Keywords: Prevalence; Attention-deficit/hyperactivity disorder; College students; Co-morbidity.

\title{
Prevalence of attention-deficit/hyperactivity disorder and co-morbid disorders among students of Cumhuriyet University
}

\author{
Onder Kavakci MD \\ Nesim Kugu MD \\ Murat Semiz MD \\ Feride Meydan MD \\ Sureyya Karsikaya MD \\ Orhan Dogan MD
}

Cumhuriyet University Medical School

Psychiatry Department, Sivas

TURKEY

\begin{abstract}
Background and Objectives: Most of the previous studies investigated prevalence of attention-deficit/hyperactivity disorder (ADHD) among university students with self report measures. Present study investigated actual prevalence of ADHD and comorbid disorders among university students in Cumhuriyet University of Sivas in Turkey.

Methods: In the first stage, 980 university students filled in the Adult ADHD Self-Report Scale and socio-demographic form, 79 of whom were above the cut-off score of Adult ADHD Self-Report Scale, considered as possible ADHD. They were evaluated in the second stage via structured interview SCID I, SCID II, Adult ADHD Module of MINI Plus. In addition, subjects filled in the self report Adult ADD/ADHD DSM IV-Based Diagnostic Screening and Rating Scale.

Results: The self report ADHD prevalence rate was $10.1 \%$ and the actual prevalence rate of ADHD among the university students was calculated $6.1 \%$. The prevalence of ADHD was greater among male than female (7.0\% vs. $5.5 \%)$. Among the male students inattentive subtype was $1.6 \%$, hyperactive-impulsive $0.24 \%$, combined $5.1 \%$. Female students were found to be inattentive by $1.45 \%$, hyperactive-impulsive by $0.56 \%$ and combined type by $3.48 \%$. Most of the students with ADHD had Axis I (especially depressive disorders) and Axis II disorders (especially cluster B personality disorders). ADHD diagnosis was associated with more cigarette and alcohol use, academic failure, legal problems, somatic complaints and suicide attempts. Students with ADHD were spending more time on the Internet than students without ADHD. Only one student diagnosed with ADHD reported to have had previous ADHD diagnosis.

Conclusions: ADHD is common among university students. Having a diagnosis of ADHD in early adulthood seems to be associated with psychological, social, and academic problems.
\end{abstract}




\section{Introduction}

Attention-deficit/hyperactivity disorder (ADHD) is characterized by an inability to sustain attention, impulsivity, and hyperactivity, and the symptoms are usually recognized before seven years of age ${ }^{1}$. Current knowledge from longitudinal data suggests that the majority of children and adolescents diagnosed with ADHD display symptoms in adolescence and adulthood ${ }^{2-4}$. ADHD affects approximately $3-7 \%$ of the school-aged population $^{1}$ and $4 \%$ of the adult population ${ }^{5,6}$. Several studies have shown an enormous impact of ADHD on the life of the affected person, which results in impairments in multiple domains of adaptive functioning, such as educational and occupational performance and social relationship, as well as an increased risk for additional psychiatric disorders ${ }^{7-9}$. Data from several studies show that up to 89\% of adults with ADHD have had additional psychiatric diagnoses during their lifetime, with affective disorders, substance use disorders (SUD), and eating disorders being the most prevalent ${ }^{5,9,10}$.

The co-morbidity of ADHD and personality disorders has been less frequently studied than the association with Axis-I disorders. However, there are few studies concerning co-morbidity of antisocial personality disorders (APD) and ADHD, with data from longitudinal and cross-sectional studies pointing to an increased co-occurrence of the two disorders, with up to $23 \%$ of young adults with ADHD presenting co-morbid $\mathrm{APD}^{7,8}$.

Recently, college students with ADHD have begun to receive more attention. Findings from college samples suggest that in comparison to the general college population, college students with ADHD are at greater risk for academic and psychological difficulties and for misuse of prescribed stimulant treatment ${ }^{11}$. Data from college stu- dents have shown that students who self-reported high symptoms of ADHD used significantly fewer academic coping behaviors, were less organized and less methodical, had lesser self-control or self-disciplinary behaviors, and procrastinated significantly more than their low-symptom peers ${ }^{12}$.

Although many studies examined the prevalence of ADHD among children and adolescents, relatively few studies investigated prevalence of ADHD among college students. A cross-cultural study, Norvilitis et al. investigated ADHD symptoms among college students in China and US. They reported that $4.4 \%$ of Americans students and $7.8 \%$ of Chinese students reported significant and current ADHD symptoms ${ }^{13}$. The actual number of college students with ADHD is unknown. Approximately $2 \%$ to $8 \%$ of college students in the U.S. report clinically significant levels of ADHD symptoms ${ }^{14}$. Researchers suggested that the prevalence of these symptoms varies depending on statistical criteria used to determine clinical significance.

Further, ADHD is a common disorder and associated with high rates of psychiatric co-morbidity but have not been investigated sufficiently in university population. Present study sought to evaluate four hypotheses:

1. The actual prevalence of ADHD among Cumhuriyet University students would be within the range reported from adults' prevalence rates.

2. Students with ADHD would have similar rates of Axis I and Axis II diagnosis with adults.

3. Students with ADHD would have higher rates of smoking, drinking, internet use and suicide attempts than those without ADHD.

4. Students with ADHD would have higher rate of grade repetition, legal problems than without. 


\section{Methods}

\section{Participants}

Cumhuriyet University (CU) was founded in 1974 in Sivas which is located in central Anatolia in Turkey, city's center population was 300,795 according to the census data of 2009. Sivas, having more traditional attitudes, is located in a less-industrialized part of Turkey with low education level, high unemployment rate. CU has nine faculties and three institutes. The total number of students on the Cumhuriyet University campus was 19,196 . Of these students, 8,364 were female, and 10,832 were male. The subjects for this research were selected from students enrolled in university program on the Cumhuriyet University Central Campus. The Directorate of the Cumhuriyet University Student Services selected the students according to faculty, university program, and class. In our study, target was to achieve $7 \%$ of the total number of students from all of the classes. When the students were identified and placed into sample groups, the plan was to reach the $1^{\text {st }}, 2^{\text {nd }}, 3^{\text {rd }}$, and $4^{\text {th }}$ year classes of every program to represent each university program and each class. Of the total number of students, 292 students who were in the $5^{\text {th }}$ and $6^{\text {th }}$ years of medical school were not included in the study in order to attain equal sample groups. Our study population is composed of 18,904 students. Our goal was to reach 1,022 students.

Simple random sampling method was used to obtain a representative sample of university population. From the 1,022 students who were informed about the study, 42 students $(3.7 \%)$ declined to participate in the study. Thus, 980 students participated in the study. Of the study participants, $55.9 \%$ (548) were male, and $44.1 \%$ (432) were female, with an age range of 17-44 years (mean age, $21.4 \pm 2.3$ years).

\section{Procedure}

This research was carried out on the Central Campus of the Cumhuriyet University. Subjects were selected by using the simple random sampling method. Self-report measures were delivered to previously identified university classrooms. The socio-demographic information form and ASRS were given to 980 students who agreed to participate and gave informed consent. Participation took an estimated 10 to 15 minutes. In the second stage, the SCID-I, SCID II, and ADHD module of MINI Plus were administered to students who scored higher than the cut-off score of 40 (1.5 standard deviation above the mean) on the ASRS for diagnosis. Symptoms of ADHD in both childhood and adulthood were examined with MINI Plus, a form of structured interview. These subjects also filled Adult ADD/ADHD DSM-IV-Based Diagnostic Screening and Rating Scale. Diagnosis of ADHD was present in 48 students. Structured interviews were administered by two experienced psychiatrist (Dr FM and Dr SK).

Only one student reported that has ADHD diagnosis before the present study and no one reported that use any medication for ADHD.

Approval by the institutional ethical committee of the Cumhuriyet University Faculty of Medicine was obtained prior to the study.

\section{Measures}

Socio-demographic Data Form. Questions related to participants' age, gender, marital status, family income, cohabitants in the house, medical history of the subject and his family, perinatal risk factors for ADHD, maternal smoking and alcohol consumption during pregnancy, parental marital discord, Internet habits, and legal history were included in this form. 
Adult ADHD Self-Report Scale [ASRS $]^{15}$. The ASRS is an 18-item self-report inventory where 9 items are designed to tap ADD symptoms, and 9 items are designed to tap hyperactivity symptoms. Each item is rated on a 5-point Likert scale ranging from "never" to "very often." Concerning the diagnosis of ADHD, screening was performed using the ADHD Self-Report Scale (ASRS), including 18 questions about frequency of recent DSM-IV Criterion A symptoms of adult ADHD, and the diagnosis of ADHD was then confirmed according to DSM-IV diagnostic criteria. The psychometric properties of the Turkish ASRS have been established by using university students ${ }^{16}$.

Structured Clinical Interview for DSMIV Axis-I Disorders. SCID-I is a semi-structured clinical interview inventory developed for the diagnosis of DSM-IV Axis-I disorders. First et al. ${ }^{17}$ developed this form; Ozkurkcugil et al. adapted it to Turkish population, and the reliability findings were reported by the same author ${ }^{18}$.

Structured Clinical Interview for DSMIII-R Personality Disorders (SCID-II). SCID-II investigates 12 types of DSM-III-R personality disorders ${ }^{19}$. The validity and reliability studies of SCID-II have been made by Coşkunol et al. in Turkey ${ }^{20}$.

Adult ADD/ADHD DSM IV-Based Diagnostic Screening and Rating Scale. This was developed by Turgay. Günay et al. demonstrated that Adult ADHD Rating Scale Turkish version is valid and reliable ${ }^{21}$.

MINI. The MINI is a brief structured interview designed to diagnose Axis I and Axis II according to DSM-IV and ICD-10 criteria. For the purposes of this study, we used the sections of the instrument (MINI-Plus version) ADHD module. This module evaluates diagnosis of child age and adult ADHD according to DSM IV criteria ${ }^{22}$.

\section{Statistical Analysis}

ADHD was included as the dependent variable, and socio-demographic variables were included as independent variables. The statistical analyses were done using the SPSS (version 15.0) computer program; chi-square and Fischer's exact tests were applied. Statistical power was 0.8015 and effect size was 0.02. Statistical significance was defined at the $\mathrm{p}<0.05$ level.

\section{Results}

Nine hundred eighty students participated in the study. Of the study participants, $55.9 \%$ (548) were male, and $44.1 \%$ (432) were female, with an age range of 17-44 years (mean age, $21.4 \pm 2.3$ years). For ASRS; mean scores was $26.82 \pm 8.46$. When 1.5 SD above the mean was accepted as ASRS cut-off (those above 40 points), 99 students were eligible for the second stage. Self-report ADHD prevalence was $10.1 \%$ according to ASRS cut-off score. Seventy-nine of this 99 eligible subjects accepted further evaluation. There was no statistically significant difference in gender, marital status, family income, and psychiatric or medical histories of the subjects and their families between those with or without ADHD ( $p>0.05$ ). The rate of participants who were diagnosed with ADHD was $4.9 \%(n=48)$. ADHD was found in 48 of 79 students, if 20 students who could not be interviewed were calculated too, adjusted prevalence of ADHD can be calculated as $6.1 \%$.

The distributions of socio-demographic characteristics for those with and without ADHD are shown in Table 1. 
Table 1

Students' Socio-demographic data

\begin{tabular}{llrrrrrr} 
& & Without ADHD & $\%$ & ADHD & $\%$ & total & P \\
\hline Sex & Male & 520 & 94.9 & 28 & 5.1 & 548 & 0.730 \\
& Female & 412 & 95.4 & 20 & 4.6 & 432 & \\
\hline Habits & None & 673 & 72.4 & 22 & 45.8 & 695 & $0.001^{*}$ \\
& Smoking & 161 & 17.3 & 17 & 35.4 & 178 & \\
& Alcohol & 25 & 2.7 & 3 & 6.3 & 28 & \\
& Smoking + alcohol & 70 & 7.5 & 6 & 12.5 & 76 & \\
\hline Any Somatic disease & & 18 & 1.9 & 4 & 8.3 & 22 & $0.019^{*}$ \\
\hline Grade failure & & 163 & 17.5 & 15 & 31.3 & 178 & $0.016^{*}$ \\
\hline Legal problem & None & 815 & 87.5 & 32 & 66.7 & 847 & $0.001^{*}$ \\
& One time & 66 & 7.1 & 9 & 18.8 & 75 & \\
\hline Lifelong & Two or more & 50 & 5.4 & 7 & 14.6 & 57 & \\
\hline Suicide attempt & None & 906 & 97.5 & 44 & 91.7 & 950 & $0.009^{*}$ \\
\hline Internet use hour/day & One time & 17 & 1.8 & 4 & 8.3 & 21 & \\
& Two or more & 6 & 0.6 & 0 & 0.0 & 6 & \\
\hline & 2-2 & 561 & 61.2 & 25 & 52.1 & 586 & $0.001^{*}$ \\
& 4 or more & 257 & 28.0 & 9 & 18.8 & 266 & \\
\hline
\end{tabular}

$* \mathrm{p}<0.05$.

Students with ADHD reported significantly more physical illness, academic failure, legal problems, lifetime suicide attempts, and more Internet use $(\mathrm{p}<0.05)$.

Only one student diagnosed with ADHD in this study reported to have had ADHD diagnosis previously.

\section{Axis I disorders}

The most commonly diagnosed lifetime Axis-I disorders in ADHD groups were depressive disorders $(58.35 \%)$ and anxiety disorders $(24.6 \%)$. The rate of major depressive disorder was $52.1 \%(\mathrm{n}=25)$. Current and lifetime DSM-IV Axis-I disorders are shown in Table 2.

\section{Table 2}

Current and Lifelong Axis I psychiatric co-morbidity in students with ADHD

\begin{tabular}{lcc} 
& $\mathrm{N}$ & $\%$ \\
\hline Major depression & 25 & 52.1 \\
Social anxiety disorder & 5 & 10.42 \\
Panic disorder & 4 & 8.3 \\
Adjusment disorder & 4 & 8.3 \\
Distimic disorder & 3 & 6.25 \\
Bipolar I & 1 & 2.08 \\
Generalized anxiety & 1 & 2.08 \\
Special Phobia & 1 & 2.08 \\
OCD & 1 & 2.08 \\
\hline
\end{tabular}

OCD: obsessive compulsive disorder. 


\section{Axis II disorders}

The most frequently diagnosed Axis II disorders were cluster $\mathrm{C}$ personality disorders (35.42\%). The rate of cluster A personality disorders was $8.3 \%(n=4)$. Co-morbid DSMIV Axis II disorders are shown in Table 3.

\section{Table 3}

Axis II psychiatric co-morbidity in students with ADHD

\begin{tabular}{lll} 
& $\mathrm{N}$ & $\%$ \\
\hline Avoidant PD & 7 & 14.58 \\
Borderline KB & 6 & 12.5 \\
OCPD & 5 & 10.42 \\
Dependant PD & 5 & 10.42 \\
Paranoid PD & 3 & 6.25 \\
Antisocial PD & 3 & 6.25 \\
Pasive Agressive PD & 2 & 4.16 \\
Schizotypal PD & 1 & 2.08 \\
Histrionic PD & 1 & 2.08
\end{tabular}

PD: personalty Disorder, OCPD: Obsessive Compulsive Presonality Disorder.

ADHD subtypes were determined according to Adult ADD/ADHD DSM-IV-Based Diagnostic Screening and Rating Scale. The distribution of students with ADHD according to subtype is shown in Table 4 and adjusted distributions according to study population is shown in Table 5 .

\section{Discussions}

To date, there have been university surveys evaluating prevalence of ADHD based on self-reports, but this seems to be the first study reporting ADHD prevalence in university students with a clinical interview for ADHD and co-morbid diagnoses. Structured diagnostic interviews increase the reliability and power of the prevalence studies.

Among students in Cumhuriyet University in Turkey, $6.1 \%$ of the students were clinically diagnosed with ADHD. Approximately 2 to $8 \%$ of the college population has been reported to have clinically significant levels of ADHD symptomatology ${ }^{14}$. Do an et al. ${ }^{23}$ found that self-reported ADHD prevalence rates were $2.6 \%$ among university students in Turkey with ASRS cut-off accepted as 2 SD above the mean and $6 \%$ with ASRS cut-off accepted as $1.5 \mathrm{SD}$ above the mean. The findings of the current study are similar to those reported in a recent study.

A large study by DuPaul et al. ${ }^{24}$ examined of ADHD symptom prevalence in college population with self report rating 1209 college students across three countries (United states, Italy and New Zealand). They found that $2.9 \%$ of male students from US, $7.4 \%$

Table 4

Distributions of the subjects according to ADHD subtypes

\begin{tabular}{lcccccc} 
Sex & Inattentive & $\%$ & Hyperactive-impulsive & $\%$ & Combined & $\%$ \\
\hline Male & 7 & 14.58 & 1 & 2.08 & 21 & 43.75 \\
Female & 5 & 10.41 & 2 & 4.17 & 12 & 25 \\
Total & 12 & 25 & 3 & 6.25 & 33 & 68.75 \\
\hline
\end{tabular}

Table 5

Adjusted distributions of ADHD subtypes according to study population

\begin{tabular}{|c|c|c|c|c|c|c|c|c|}
\hline Sex & Inattentive & $\%$ & Hyperactive-impulsive & $\%$ & Combined & $\%$ & Total & $\%$ \\
\hline Male & 8.77 & 1.6 & 1.25 & 0.24 & 26.3 & 5.1 & 36.32 & 7.0 \\
\hline Female & 6.27 & 1.45 & 2.5 & 0.56 & 15.04 & 3.48 & 23.8 & 5.5 \\
\hline Total & 15.03 & 1.53 & 3.76 & 0.38 & 41.35 & 4.22 & 60.12 & 6.1 \\
\hline
\end{tabular}


of male Italian students and $8.1 \%$ of male students from New Zealand reported significant ADHD symptoms. Female students reported $3.9 \%$ from US, $0 \%$ from Italy and $1.7 \%$ from New Zealand significant ADHD symptoms. In other study of college population; Heilingstein et al. reported that inattentive type was the most common among university students ${ }^{25}$. Present study found inattentive and combined type more in men, and hyperactive type was found more in female students. The majority of students had combined type of ADHD. The reasons for this difference might be the scale used to assess ADHD subtypes and the characteristic of each studied sample.

With ASRS scale, 10.1 percent of the students meet the adult ADHD criteria, and this diagnosis was confirmed with clinical diagnosis in approximately $6,1 \%$. This evidence suggests, for this sample, about $60 \%$ of the identified subjects by ASRS scale has actually adult ADHD.

Relatively few studies have investigated the psychological functioning of college students with ADHD. Heilingstein and Keeling made a systematic chart review and further investigation for 42 students who seek treatment and after the inspection of the charts, these students were diagnosed with $\mathrm{ADHD}^{26}$. In these students, most common presenting problem was ADHD symptoms (55\%), followed by mood symptoms $(21 \%)$, academic under achievement (14\%), and non specific learning disability $(10 \%)$. Comorbid problems were reported in $55 \%$ of the samples. The rate of the depressive disorders was $26 \%$, drug or alcohol abuse or dependence $26 \%$, legal difficulties $12 \%$, anxiety disorders $5 \%$, learning disabilities $2 \%$ and eating disorders $2 \%$. Similarly, in this study, there were high rates of Axis I and Axis II disorders in students with ADHD. The most common Axis I disorders were
Major Depressive Disorder (MDD), anxiety disorders, and dystimic disorders. Many studies have reported higher rates of Axis I and Axis II disorders in patients with adult ADHD than those without ADHD ${ }^{2,5,27}$. The National Co-morbidity Survey Replication (NCSR) found that $38.3 \%$ of respondents with ADHD had co-morbid mood disorder, $47.1 \%$ had co-morbid anxiety disorder, $15.2 \%$ had Substance Use Disorder (SUD), and $19.6 \%$ had other impulse-control disorders $^{5}$. Results of ADHD co-morbidity studies were similar to those from the NCS-R: $30 \%$ to $35 \%$ of patients with ADHD had major depression, $40 \%$ to $50 \%$ had anxiety disorders, and $40 \%$ to $50 \%$ had SUD ${ }^{28,29}$. Many studies have found that students with ADHD have had more depressive symptoms than others ${ }^{14,26,30}$. In a review of studies in community samples by Angold et al., it has been reported that the rate of MDD in youths with ADHD was 5.5 times higher than those without $\mathrm{ADHD}^{31}$. A common notion is that the cumulative effects of ADHD-related impairments and the negative environmental circumstances may lead to depression in some patients with $\mathrm{ADHD}^{32}$.

Only one patient was diagnosed with bipolar disorder $(2.08 \%)$ in this study. Relationship between bipolar disorder and ADHD is controversial. A systematic review by Wingo and Ghaemi reported that co-morbidity of bipolar disorder and ADHD is fairly common; however, this co-morbidity has been insufficiently studied ${ }^{33}$. Cross-sectional design of this study and collection of data in a nonclinical population might be the reason for the low rate of bipolar diagnosis in subjects with ADHD. Long-term studies in patients with ADHD could be more informative and more reliable to understand this co-morbidity. Among students with ADHD, none was diagnosed with SUD. In Turkey, particularly in this region of the country, al- 
cohol and other substance use may be lower or may not have been reported because of traditional and religious reasons.

Among students with ADHD, 22.9\% were diagnosed with an Axis II disorder, most common of which were cluster $\mathrm{C}$ personality disorders [ $14.58 \%$ avoidant, $10.42 \%$ Obsessive Compulsive Personality Disorder (OCPD), 10.42\% dependent]. Borderline personality disorder was the second most common Axis II diagnoses. APD rates were $6.25 \%$. Studies report an increased risk of cluster B (primarily borderline and APD) and $\mathrm{C}$ personality disorders in patients with $\mathrm{ADHD}^{28,34}$. Miller and colleagues showed that individuals diagnosed with childhood ADHD were at increased risk for personality disorders in late adolescence, specifically borderline, antisocial, avoidant, and narcissistic personality disorders ${ }^{35}$. The findings of this study, with a high rate of class B and C personality disorders in subjects with ADHD is fairly consistent with the literature.

Because there have been no study evaluating Axis II diagnoses among university students, comparisons could not be possible. The rate of antisocial personality disorder reported in clinical and community samples was higher than the rate reported in this study. Nonetheless, alcohol use and legal problems were higher in subjects with ADHD compared with those without ADHD. Diagnosis of antisocial personality disorder rates higher than this study results is found in clinic and community studies. To our knowledge, no study has evaluated Axis II pathology among university students with ADHD, so this could not be compared. However, legal problems and smoking and alcohol use were higher in students with ADHD than those without ADHD in this study.

Disruptive behaviors, such as aggression, impulsivity, violence, antisocial behavior, and psychopathy, have been shown to be associ- ated with having a diagnosis of $\mathrm{ADHD}^{36}$. Studies with college students showed that students with ADHD experienced more legal problems than those without $\mathrm{ADHD}^{14,26}$. Similarly, in this study, students with ADHD reported more legal problems than those without ADHD.

In this study, lifetime suicide attempts rate among students with ADHD were significantly higher than those without ADHD. Studies have found significant association between ADHD and suicidal behavior ${ }^{37,38}$. ADHD was associated with high co-morbidity with depression and personality disorders, which might be factors increasing the risk of suicide.

Students with ADHD reported significantly more physical illness than those without ADHD. Similar to these findings, studies have reported more medical problems, more emergency room visits ${ }^{39}$, and more health expenditure in youth and children with $\mathrm{ADHD}^{40}$.

Students with ADHD reported significantly more grade repetition. ADHD is characterized by impairments in academic functioning, memory, and executive functions ${ }^{28}$, which might be the reason for higher rate of academic failures and repetitions among ADHD subjects.

In this study, students have reported spending several hours per day surfing the Internet. The ADHD group spent significantly more time in the Internet than those without ADHD. Approximately $30 \%$ of this group spent more than 4 hours per day surfing the Internet. Significant associations have been reported between the level of ADHD symptoms and the severity of Internet addiction ${ }^{41}$.

In students with ADHD, smoking and alcohol use were significantly more than those reported in other studies ${ }^{27,30}$. This study did not assess the severity of these habits. 
The relationship between smoking, alcohol use, and ADHD has been well known; for example, Rabiner et al. reported that students with ADHD were 2.5-3.5 times more likely to have smoked cigarettes than students without $\mathrm{ADHD}^{30}$.

In this study, 48 students were diagnosed with ADHD, despite receiving psychiatric help for other reasons, only one was previously diagnosed with ADHD. The reason of this may be recognizing of ADHD may not be enough in Turkey. Nur and Kavakci, reported in their study that ADHD is not known sufficiently among the primary school teachers. Reasons for missing the diagnosis of ADHD should be investigated by physicians ${ }^{42}$.

In this sample, all of the students diagnosed with ADHD were invited to the hospital for psycho-education and standard clinical care. Few of the invited students $(n=5)$ received these services and all of them dropped out.

\section{Limitations}

One of the limitations of this study is the lack of assessment of the group whose ASRS score is under established cut off value for axis I and II diagnoses. Another limitation of the present study was that interviews were conducted only with the students. For the diagnosis of ADHD, information is required from many sources, such as parents, teachers. Moreover, this study did not examine students' detailed psychological, social and academic problems.

Nevertheless, in this study, the prevalence rate of ADHD among university students in Cumhuriyet University was found to be 6.1\%. Diagnosis with ADHD has been associated with more cigarette and alcohol use, academic failures, legal problems, somatic complaints and lifetime suicide attempts. Students with ADHD spent more time in the Internet than those without ADHD. Furthermore, students with ADHD often had Axis I (especially depressive disorders) and Axis II disorders. In students having impulsive behaviors, such as substance use, legal problems, class B personality features, depression, and academic failures, ADHD should be considered. Prior to the study, some of the students diagnosed with ADHD have received psychiatric treatment for some reason, but ADHD diagnosis mostly has been omitted. Further research is needed in this area because students with ADHD have more psychological, social, and academic problems.

\section{References}

1. American Psychiatric Association. Diagnostic and Statistical manual of Mental Disorders, Fourth Edition, Text Revision. Washington, DC: American Psychiatric Association; 2000.

2. Spencer T, Biederman J, Wilens T, Faraone SV. Is attention-deficit hyperactivity disorder in adults a valid disorder? Harv Rev Psychiatry 1994; 1: 326-335.

3. Biederman J, Mick E, Faraone SV. Age-dependent decline of symptoms of Attention Deficit Hyperactivity Disorder: impact of remission definition and symptom type. Am J Psychiatry 2000; 157: 816-818.

4. Barkley RA, Fischer M, Smallish L, Fletcher K. The persistence of attention deficit/hyperactivity disorder into young adulthood as a function of reporting source and definition of disorder. J Abnorm Psychol 2002; 111: 279-289.

5. Kessler RC, Adler LA, Barkley R, Biederman J, Conners CK, Faraone SV. The prevalence and correlates of adult ADHD in the United States: results from the National Comorbidity Survey Replication. Am J Psychiatry, 2006; 163: 716-723.

6. Faraone SV, Antshel KM. Diagnosing and treating attention-deficit/hyperactivity disorder in adults. World Psychiatry 2008; 7(3): 131-136.

7. Weiss G, Hechtman L, Milroy T, Perlman T. Psychiatric status of hyperactives as adults: a controlled prospec- 
tive 15-year follow-up of 63 hyperactive children. J Am Acad Child Adolesc Psychiatry 1985; 24: 211-220.

8. Manuzza S, Klein RG, Bessler A, Malloy P, La Padula M. Adult outcome of hyperactive boys. Educational achievement, occupational rank, and psychiatric status. Arch Gen Psychiatry 1993; 50(7): 565-576.

9. Biederman J, Monuteaux MC, Mick E, Spencer T, Wilens TE, Silva JM, et al. Young adult outcome of attention deficit hyperactivity disorder: a controlled 10-year follow-up study. Psychol Med 2006; 36: 167-179.

10. Fayyad J, De Graaf R, Kessler R, Alonso J, Angermeyer M, Demyttenaere K, et al. Cross-national prevalence and correlates of adult attention-deficit hyperactivity disorder. Br J Psychiatry 2007; 190: 402-409.

11. Weyandt LL, DuPaul GJ. ADHD in college students: Developmental findings. Dev Disabil Res Rev 2008; 14: 311-319.

12. Turnock P, Rosen LA, Kaminski PL. Differences in academic coping strategies of college students who self-report high and low symptoms of attention deficit hyperactivity disorder. J Coll Stu Dev 1998; 39: 484-493.

13. Norvilitis JM, Ingersoll T, Zhang J, Jia S. Self-reported symptoms of ADHD among college students in China and the United states. J Atten Disord 2008; 11: 558-567.

14. DuPaul GJ, Weyandt LL, O’Dell SM, Varejao M. College students with ADHD: current status and future directions. J Atten Disord 2009; 13: 234-250.

15. Kessler RC, Adler L, Ames M, Demler O, Faraone S, Hiripi E, et al. The World Health Organization Adult ADHD Self-Report Scale (ASRS): a short screening scale for use in the general population. Psychol Med 2005; 35 : 245-256.

16. Dogan S, Oncu B, Saracoğlu GV, Kucukgoncu S. Validity and reliability of the Turkish version of the Adult ADHD Self-Report Scale (ASRS-v1.1). Anatolian Journal of Psychiatry 2009; 10(2): 77-87.

17. First MB, Spitzer RL, Gibbon M, Williams JBW. Structured Clinical Interview for DSM-IV. Clinical Version (SCID I/CV). Washington, D.C.: American Psychiatric Press; 1997.

18. Ozkurkcugil A, Aydemir O, Yildiz M, Esen Danacı A, Köroğlu E. The reliability and adaptation to Turkish of Structured Clinical Interview for DSM IV Axis-I Disorders. Ilac ve Tedavi Dergisi 1999; 12: 233-236.

19. Skodol AE, Rosnick L, Kellman D. Development of a procedure for validating Structured Assessments of Axis II. In: Oldham JM, editor. Personality Disorders: New Perspectives in Diagnosis. Washington, D.C.: American Psychiatric Press; 1990. p. 1316-1327.
20. Coskunol H, Bagdiken I, Sorias S. The Reliability in Personality Disorders of SCID-II, vol. 28. In: Congress of National Psychiatry; Ankara; 1992.

21. Gunay S, Savran C, Aksoy UM, Maner F, Turgay A, Yargıç I. The norm study, transliteral equivalence, validity, reliability of adult hyperactivity scale in Turkish adult population. Türkiye'de Psikiyatri 2006; 8: 98-107.

22. Sheehan DV, Lecrubier Y, Sheehan KH, Amorim P, Janavs J, Weiller E, et al. The Mini-International Neuropsychiatric Interview (M.I.N.I.): the development and validation of a structured diagnostic psychiatric interview for DSM-IV and ICD-10. J Clin Psychiatry 1998, 59 (Suppl 20): 22-33.

23. Doan S, Öncü B, Saraçolu GV, Küçükgöncü S. Prevalence of ADHD Symptoms in University Students and Developmental, Academic and Psychological Factors Related to Symptom Level. Türkiye'de Psikiyatri 2008; 10(3): 109-115.

24. DuPaul GJ, Schaughency EA, Weyandt LL, Tripp G, Kiesner J, Ota K, et al. Self-report of ADHD symptoms in university students: Cross-gender and cross-national prevalence. J Learn Disabil 2001; 34: 370-379.

25. Heiligenstein E, Conyers LM, Berns AR, Miller MA. Preliminary normative data on DSM-IV attention deficit hyperactivity disorder in college students. J Am Coll Health 1998; 46(4): 185-188.

26. Heiligenstein E, Keeling RP. Presentation of unrecognized attention deficit hyperactivity disorder in college students. J Am Coll Health 1995; 43(5): 226-228.

27. Cumyn L, French L, Hechtman L. Comorbidity in adults with attention-deficit hyperactivity disorder. Can J Psychiatry 2009; 54: 673-683.

28. Biederman J, Faraone SV, Spencer T. Patterns of psychiatric comorbidity, cognition, and psychosocial functioning in adults with attention deficit hyperactivity disorder. Am J Psychiatry 1993; 150: 1792-1798.

29. Shekim WO, Asarnow RF, Hess E, Zaucha K, Wheeler N. A clinical and demographic profile of a sample of adults with attention deficit hyperactivity disorder, residual state. Compr Psychiatry 1990; 31(5): 416-425.

30. Rabiner DL, Anastopoulos AD, Costello J, Hoyle RH, Swartzwelder HS. Adjustment to college in students with ADHD. J Atten Disord 2008; 11(6): 689-699.

31. Angold A, Costello EJ, Erkanli A. Co-morbidity. J Child Psychol Psychiatry 1999; 40: 57-87.

32. Daviss WB. A review of co-morbid depression in pediatric ADHD: etiology, phenomenology, and treatment. J Child Adolesc Psychopharmacol 2008; 18(6): 565-571.

33. Wingo AP, Ghaemi SN. A systematic review of rates and diagnostic validity of comorbid adult attention-de- 
ficit/hyperactivity disorder and bipolar disorder. J Clin Psychiatry 2007; 68: 1776-1784.

34. Miller TW, Nigg JT, Faraone SV. Axis I and II comorbidity in adults with ADHD. J Abnorm Psychol 2007; 116: 519-528.

35. Miller CJ, Flory JD, Miller SR, Harty SC, Newcorn JH, Halperin JM. Childhood attention-deficit/hyperactivity disorder and the emergence of personality disorders in adolescence: a prospective follow-up study. J Clin Psychiatry 2008; 69: 1477-1484.

36. Retz W, Rösler M. The relation of ADHD and violent aggression: What can we learn from epidemiological and genetic studies? Int J Law Psychiatry 2009; 32: 235-243.

37. Goldston DB, Daniel SS, Erkanli A, Reboussin BA, Mayfield A, Frazier PH, et al. Psychiatric diagnoses as contemporaneous risk factors for suicide attempts among adolescents and young adults: developmental changes. J Consult Clin Psychol 2009; 77(2): 281-290.

38. Manor I, Gutnik I, Ben-Dor DH, Apter A, Sever J, Tyano S, et al. Possible association between attention deficit hyperactivity disorder and attempted suicide in adolescents - a pilot study. Eur Psychiatry 2010; 25(3): 146-150.
39. Cuffe SP, Moore CG, McKeown R. ADHD and health services utilization in the national health interview survey. J Atten Disord 2009; 12(4): 330-340.

40. Jones DE, Foster EM; Conduct Problems Prevention Research Group. Service use patterns for adolescents with ADHD and comorbid conduct disorder. J Behav Health Serv Res 2009; 36(4): 436-449.

41. Yoo HJ, Cho SC, Ha J, Yune SK, Kim SJ, Hwang J, et al. Attention deficit hyperactivity symptoms and internet addiction. Psychiatry Clin Neurosci 2004; 58(5): 487-494.

42. Nur N, Kavakci O. Elementary school teachers' knowledge and attitudes related to attention deficit hyperactivity disorder. Health Med 2010; 2(4): 350-355.

Author for correspondence:

Dr. Onder Kavakci

Psikiyatri AD

Cumhuriyet Universitesi Tip Fakultesi

TR-58140 Sivas, Turkey

Fax: +90 3642581305

E-mail: okavakci@yahoo.com 